\title{
Self-esteem and the need for social approval*
}

\author{
CHARLES KIMBLE and ROBERT HELMREICH \\ The University of Texas at Austin, Austin, Tex. 78712
}

This experiment attempted to show that high and low self-esteem persons have a greater need for approval from others than do moderate self-esteem people. Ss from the three self-esteem groups evaluated a fictitious "other S," either anonymously or believing that the other would see the evaluation and would meet the $S$ after the evaluation. A significant interaction between self-esteem and the experimental manipulation was obtained on personal liking. The hypothesis was supported. Additional explanations are proposed to account for the reactions of the low self-esteem Ss.

Cohen (1959) proposed a theoretical view of self-esteem that others have used as a basis for research. He approached the difference between high and low self-esteem individuals in terms of degree of openness to change and negative selfevaluation. He stated that high self-esteem persons use avoidance defenses in coping with their environment. Low individuals use expressive defenses. High self-esteem persons respond so as to maximize their regard for their performance, while low self-esteem individuals behave in a way that denigrates their performance. The moderate self-esteem group was seen as least inclined to use defenses and as the best adjusted socially of the three groups.

Leventhal \& Perloe's (1962) study on self-esteem and persuasibility supported Cohen's ideas about the types of defenses high and low self-esteem people use. High self-esteem persons were influenced more by optimistic communications and low self-esteem Ss by pessimistic messages. They did not use a moderate self-esteem group.

Silverman (1964a, b) investigated the effects of success and failure experiences on different self-esteem groups. One interesting finding of Silverman's (1964a) study was that the relationship between self-esteem and persuasibility under the no-success no-failure control condition was essentially $U$-shaped. That is, the high and low groups were more persuasible than the moderate group. In another experiment, Silverman (1964b), working from Cohen's framework, predicted that high self-esteem Ss would be more responsive to success experiences and lows would respond more to failure experiences. This expectation was confirmed. He also noted that the difference between the

*This research was funded by the Organizational Effectiveness Research Programs, Psychological Sciences Division, Office of Naval Research, under Contract No. N0001 4-67A-0126-0001 Contract Authority Identification No. NR171-804. Robert Helmreich was principal investigator. success and failure conditions was smallest for the moderate self-esteem group.

Hendrick \& Page (1970) suggested that high and low self-esteem $S s$ are more similar to each other in various response dispositions such as attraction and persuasibility than they are to moderates. Their experiment indicated that moderates were less rejecting of dissimilar others than were the high and low groups.

Other recent research has also indicated that self-esteem does not always operate in an additive or linear fashion. Helmreich, Aronson, \& LeFan (1970) replicated an experiment by Aronson, Willerman, \& Floyd (1965) using three different self-esteem groups. The other variables were competence of the person judged and whether he committed a pratfall. In the high-competent condition, they found that moderate self-esteem Ss responded like the undifferentiated groups in the previous experiment. They liked the compotent person who committed a pratfall better than one who didn't. However, committing a pratfall decreased the liking of the high and low self-esteem groups for the competent person.

These findings lead the present authors to contend that high and low self-esteem persons differ from moderates in responding to some social situations. Specifically, high and low self-esteem persons are more sensitive to evaluational feedback from other people and are more dependent on this feedback in forming their own self-evaluation. This sensitivity caused their aversive reaction to the blunder by the person in an evaluation situation, with whom they empathized, in the Helmreich et al study. This sensitivity should be manifested in a greater need for social approval. Buss (1966) contends that a person's self-esteem is basically determined by whether he receives love conditionally or unconditionally from his parents as a child. If love is given only contingent on the performance of certain behaviors, the child will not develop an appreciation for his worth. Rogers (1959) has used the concepts of conditional and unconditional regard in a similar fashion.

The present authors assume that if a person has little initial appreciation for his worth, he will be more sensitive to others' evaluations in evaluating himself. The unconditionally regarded person has high appreciation for his worth and is, therefore, less vulnerable to evaluational inputs from his environment. High and low self-esteem individuals evaluate themselves more according to how others have viewed them. If they have generally been evaluated highly by others in the past, these persons who are sensitive to evaluation from others will be high self-esteem individuals. If they have been evaluated negatively, they will be of low selfesteem. However, those who have been consistently well-regarded regardless of their behavior in their critical developmental stages have no differential reinforcement history by which they can evaluate themselves. But, being sure of their self-worth because of their consistent good treatment, they assume that they are normal or average and do not look to others for evaluation. Gergen (1971) states that some persons may develop internalized standards of comparison and are not susceptible to the appraisal of others. The present authors contend that most of these people have moderate levels of measured self-esteem.

This experiment tests the hypothesis that high and low self-esteem groups have a greater need for social approval than the moderate group. A crucial assumption was made in operationalizing the need for approval. It was assumed that most people believe that other persons will like them more if they indicate to these other persons that they like them. This assumption is consistent with the way most people view interpersonal relations; for example, Jones, Gergen, \& Davis (1962) found that people like people who have evaluated them highly. Therefore, if a person wanted to endear himself to a stranger, he would tell that stranger that he liked him. It was assumed that the difference in evaluation of a stranger between a condition in which the stranger would not see the evaluation and one in which he would was a valid index of a S's need for approval. It was originally thought that all groups would rate the stranger higher in the nonanonymous condition, with the moderate group showing the least difference between the two conditions.

\section{SUBJECTS}

Thirty-five males and 33 females 
enrolled in introductory psychology courses at the University of Texas at Austin served as Ss. 1 They had scored in the high, middle, or low quarter of the distribution on the Texas Social Behavior Inventory (Helmreich, Aronson, \& LeFan, 1970), a self-esteem scale administered at the beginning of the semester. Ss were randomly assigned to either a "postevaluation contact" group or a "no postevaluation contact" group.

\section{PROCEDURES}

When the $S$ was ushered into the cubicle, he saw a female "assistant" there. The "assistant" picked up some material and went to see if her " $S$ " had arrived.

The $E$ told the $S$ that $E$ was studying how people form impressions of others given only information about their attitudes. $E$ asked $S$ to fill out the attitude survey because $E$ also wanted information about the person giving his impressions.

The $E$ left the room, and the $S$ completed a 12-item attitude survey. The 12 statements included such issues as desegregation problems, the importance of Vietnam to U.S. security, changing sex roles, using hallucinatory agents, admission of disadvantaged students, and the encumbrances of police by "technicalities." Also included were three items on personal tastes such as preferences in music and types of leisure activities. The $\mathrm{S}$ indicated his agreement or disagreement with the statements by marking a value from -3 to +3 , with no zero point included.

After a few minutes, the $\mathbf{E}$ entered the cubicle and picked up the survey and instruction sheet, saying, "You may have to wait a few minutes while the other $S$ finishes his (her) questionnaire." The "other S" was always of the same sex as the real $S$.

After leaving the cubicle, the $E$ filled out another survey so that it disagreed with the S's on nine items. Dissimilar attitudes were indicated by marking the second or third value away from the S's rating, which was always on the opposite side of the absent zero point of the scale. Similar attitudes were indicated by marking one of the two values adjacent to the S's rating, with the limitation that it be on the same side of the midpoint. The "other S" agreed and disagreed on the same items for all Ss.

The $\mathbf{E}$ entered the cubicle, placed the attitude survey, the Interpersonal Judgment Scale (Byrne, 1971), and the instruction sheet before the $S$, and read the instructions: "This is an attitude questionnaire like the one you filled out. It was completed by a boy (girl) from another 301 section. The name has been removed so that it will not influence your impression in any way. [No-contact group] Your evaluation of the other subject will be kept strictly anonymous. I will excuse you first so that the other subject will not know who evaluated him (her). [Contact group] After you have considered the questionnaire and completed your evaluation of him (her), your evaluation will be shown to the other subject. Then you will be allowed to meet him (her), and you will be given more selected information about him (her) to see how your impressions from his attitudes fit with the added information given. [Both groups] Give your honest impressions of the other subject on the questionnaire as instructed. In case you were wondering, your questionnaire will not be evaluated by another subject; your only role in this experiment is to evaluate this subject.

The S then rated the "other S" on some personal characteristics and gave his own liking for the "other S" on the Interpersonal Judgment Scale. The most favorable rating possible was scored as a 7 ; the least as a 1 .

\section{RESULTS}

The items on the Interpersonal Judgment Scale were analyzed using 3 by 2 completely randomized design analyses of variance. Unweighted means analyses were used for the unequal cell ns.

The interaction between self-esteem and the contact manipulation on the personal liking item was significant ( $F=5.46$, df $=2 / 55, p<.008$ ). [In an analysis including the $S s$ whose data were discarded because they did not believe there was another $S$, this interaction was significant $(p<.04)]$. Figure 1 shows the interaction of the two variables.

After the significant interaction was obtained, $t$ tests were performed on the group means for personal liking. The difference between the high self-esteem no-contact group and the high self-esteem contract group was significant $(t=3.12$, df $=55, p<.01)$. The difference between the low self-esteem groups in the no-contact vs contact conditions was not significant but suggested a trend $(t=1.51$, $\mathrm{d} f=55, p<.15)$. The difference between the moderate selfesteem groups under the two contact conditions did not approach significance.

A posteriori tests using the Newman-Keuls procedure (Kirk, 1968) indicated that the difference between the high and low self-esteem groups on personal liking under no postevaluation contact was significant $(\mathrm{p}<.05)$.

The main effect of the postevaluation contact manipulation on a rating of the "other S's" adjustment was significant but not theoretically important.

\section{DISCUSSION}

The three self-esteem groups differ in need for social approval, as indicated by their responses to the no-contact and contact conditions. The contact condition showed the degree to which Ss would give socially desirable responses in order to endear themselves to the "other S." The anonymous no-contact group showed their evaluations unmitigated by the need to influence the "other S."

The interaction between self-esteem and postevaluation contact on the personal liking item supports the hypothesis that high and low Ss are more sensitive to others' evaluations than the moderate self-esteem persons. This sensitivity is reflected in the amount of difference, regardless of direction, caused by the belief that the "other S" was going to see the evaluation and meet him. However, the low self-esteem group's more negative evaluation in the contact condition was not predicted. It was expected that all groups would rate the "other S" about the same or higher in the contact condition than in the no-contact condition, depending on their need for social approval.

A cognitive dissonance explanation can account for the anomalous finding with the low self-esteem S. Aronson \& Carlsmith (1962) showed that a person attempts to make his performance consistent with his expectation of what it should be, based on past performances. Aronson (1968) has stated that imprudent behavior creates dissonance in a high self-esteem person because of his high expectations for his conduct. A low self-esteem person does not experience as much dissonance from similar behavior because he expects it.

Consistency between expectations and current behavior can be used to explain the results of this experiment. The low selfesteem person's past experience indicates to him that he will generally be evaluated poorly in a social situation. His behavior in this experiment is apparently designed to ensure a negative evaluation from others that is consistent with his expectations. That is, the typical low self-esteem S stated that he would not like the "other S," knowing that this response would cause the "other $S$ " to view him less favorably.

Jones's (1964) views on ingratiation offer possible explanations for the liking expressed by the self-esteem groups. Other-enhancement is the ingratiation tactic accessible to $\mathrm{Ss}$ in this experiment. Jones observes that low-status persons may be inhibited from using other-enhancement because it is likely to be detected as 


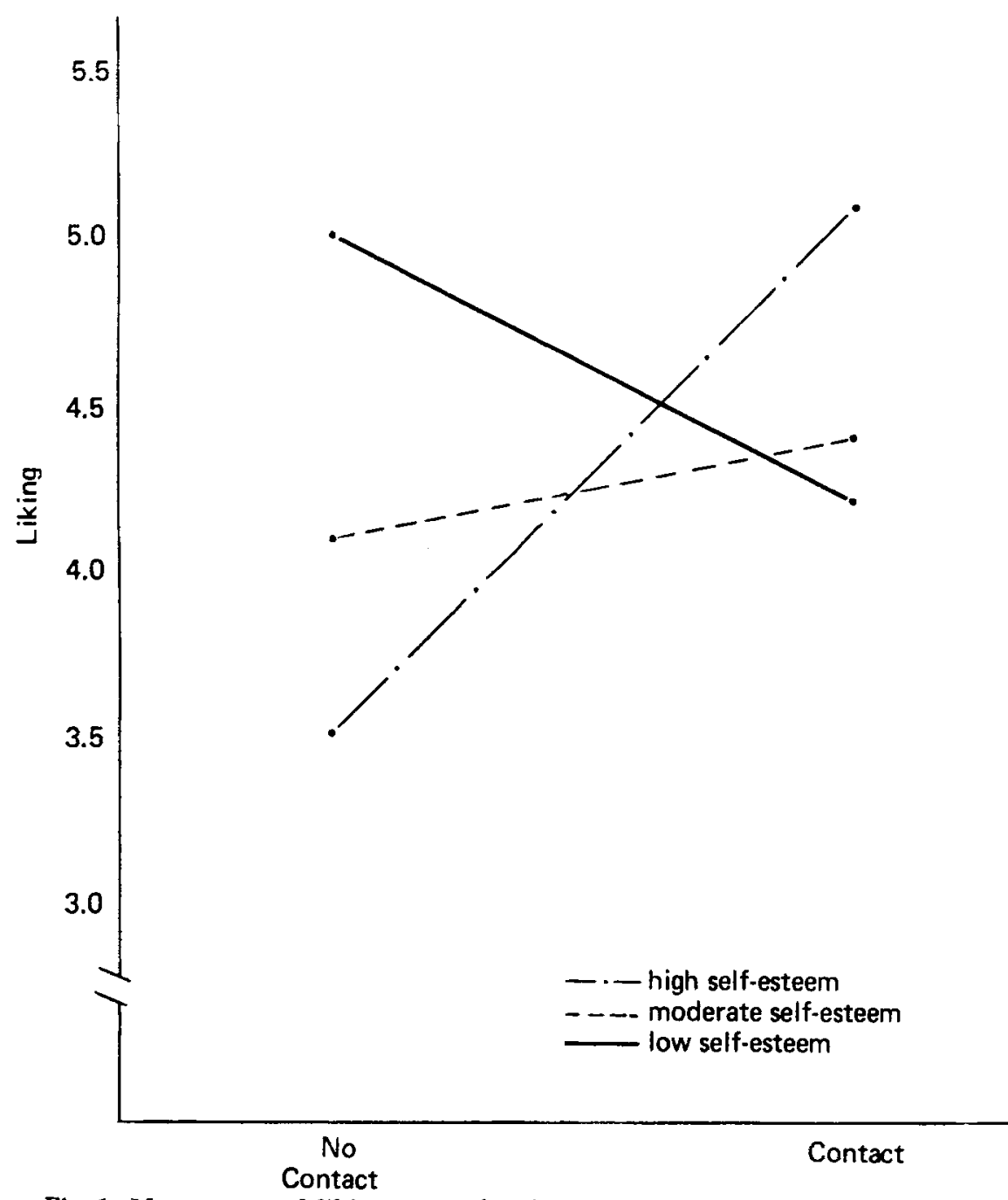

Fig. 1. Mean personal liking scores for the self-esteem groups at the two levels of postevaluation contact.

ingratiation because of their subordinate position. If low selfesteem persons can be seen as having perceived low status in social situations, Jones's observation is a possible explanation of their lower rating of the "other S." Similarly, the high self-esteem person's perceived superior status enables him to use the ingratiation technique with impunity. This formulation implies that the "other $S$ " has no ability to punish the high self-esteem $S$. Nevertheless, the high selfesteem person would have no motive to ingratiate if he did not desire the "other S's" approval. The results suggest that this approval had some reward value for high self-esteem Ss.

Jones's concept of signification suggests another explanation. Signification is Jones's term for seeking approval as a indication of one's personal value. Signification is assumed to be the ingratiation motive in this experiment. Jones suggests that the greater the ingratiator's efforts to elicit attraction, the less the signifying not distinguish between his "true" behavior and his ingratiating behavior.

The low selfesteem $S$ s gave the highest attraction rating of the "other $S$ " in the anonymous condition; the high self-esteem persons gave the lowest. It appears that Ss rated others in relation to their evaluation of themselves in this condition, which was uncolored by need for approval. Low $S s$ regarded persons with attitudes dissimilar to their own as desirable and rated them high. High self-esteem Ss rated disagreeing others negatively. Ss with moderate selfesteem rated others in a neutral fashion (mean of 4.1 on a scale with 4 as the midpoint). Ss' self-evaluation appeared to provide the anchor point for their evaluation of others. That is, if they regarded themselves as inferior, then disagreeing others were necessarily superior, and vice versa.

In an attitude similarity-attraction study, Hendrick \& Page (1970) also found that high self-esteem Ss consistently rated dissimilar others negatively. Their results were less consistent for the other two groups.

Gergen (1971, p. 73) states, "When one's esteem needs are unfulfilled, the approval of others becomes particularly valuable. It is the person most deficient in self-esteem who most exerts himself to obtain it." This experiment indicated that such an unequivocal statement may not be justified. In this experiment, high self-esteem Ss most exerted themselves to obtain approval, while low self-esteem $S s$ appeared to ingratiate themselves least. The difference between behavior under no-contact and contact conditions was used as an index of the need for approval regardless of the direction of the difference. By this criterion, the high self-esteem group indicated a strong need for approval. The results for low self-esteem $\mathrm{Ss}$, though nonsignificant, suggest that they may also have a strong need for approval. Clearly the moderate self-esteem group did not exhibit such a need.

Also, the difference between the high-and low self-esteem groups in the anonymous evaluation situation suggests that Ss' self-evaluation serves as an anchor for their evaluaticis of others.

\section{REFERENCES}

ARONSON, E. Dissonance th . $r y$ : Progress and problems. In R. Abels $\sim$ a, E. Aronson. W. McGuire, T. M. Newcomb, M. J. Rosenberg, and P. H. Tannenbaum (Eds.), Theories of cognitive consistency: A sourcebook. Chicago: Rand-McNally, 1968 .

ARONSON, E., \& CARLSMITH, J. Performance expectancy as a determinant of actual performance. Journal of Abnormal \& Social Psychology, 1962, 65, $178-182$.

ARONSON, E., WILLERMAN, B., \& FLOYD, J. The effect of a pratfall on 
increasing interpersonal attraction Psychonomic Science, 1966, 4, 227-228. BUSS, A. Psychopathology. New York: Wiley, 1966 .

BYRNE, D. The attraction paradigm. New York: Academic Press, 1971.

COHEN, A. R. Some implications of self-esteem for social influence. In C. I. Hovland and $I$. L. Janis (Eds.), Personality and persuasibility. New Haven, Conn: Yale University Press, 1959.

GERGEN, K. The concept of self. New Yok: Holt, Rinehart, \& Winston, 1971.

HELMREICH, R., ARONSON, E., \& LeFAN, J. To err is humanizing sometimes: Effects of self-esteem, competence, and a pratfall on interpersonal attraction. Journal of Personality \& Social Psychology, 1970. 16, 259-264.

HENDRICK, C., \& PAGE, H. Selfesteem, attitude similarity, and attraction. Journal of Personality, 1962. 64, 385-388.

JONES, E. E. Ingratiation: A social psychological analysis, New York: Appleton-Century-Crofts, 1964.

JONES, E. E., GERGEN, K., \& DAVIS, K. Some reactions to being approved or disapproved as a person. Psychological Monographs, 1962, 76(Whole No. 521). KIRK, R. Experimental design: Procedures for the behavioral sciences. Belmont, Calif: Brooks-Cole, 1968.

LEVENTHAL, H. \& PERLOE, S. A relationship between self-esteem and persuasibility. Journal of Abnormal \& Social Psy chology, 1962, 64, 385-388.

ROGERS, C. Therapy, personality, and interpersonal relationships. In $S$. Koch (Ed.), Psychology: A study of science. Vol. III. New York: McGraw-Hill, 1959. SILVERMAN, I. Differential effects of ego threat upon persuasibility for high and low self-esteem subjects. Journal of Abnormal \& Social Psychology, 1964a, 69, 567-572.

SILVERMAN, I. Self-esteem and differential responsiveness to success and failure. Journal of Abnormal \& Social Psychology, 1964b, 69, 115-119.

\section{NOTE}

1. Seven Ss were dropped from the analyses because they did not believe that another real $S$ was involved in the experiment. Chi-square analyses indicated whether Ss believed the deception was independent of their sex, their self-esteem group, their postevaluation contact group, or any combination of the three. The manipulation of the "other S's" attitudes was effective as all Ss were aware that the "other S's" attitudes were dissimilar to their own. 